\title{
Concept and Development of an Internet-based Newspaper for Students at the Technical University of Clausthal
}

\author{
Nils Heyer and Jorge Marx Gómez \\ Technical University Clausthal, Clausthal-Zellerfeld, Germany
}

nils.heyer@tu-clausthal.de gomez@informatik.tu-clausthal.de

\begin{abstract}
This paper deals with the conception and implementation of internet-based magazines such as online newspapers and e-journals. This topic will be discussed by the use of a precise e-newspaper implementation project called "ZeWIC". ZeWIC is short for "Zeitung der Wirtschaftsinformatik in Clausthal". It is a source of information for the students mostly for their study purposes at the Technical University of Clausthal. First there is some information given about electronic newspapers in general. Then ZeWIC is described, starting with the data model which forms the background of this special newspaper, and continuing with the particular implementation. This paper ends with a perspective about what can and will be changed or added soon to ZeWIC to improve ZeWIC's service even more.
\end{abstract}

\section{Electronic Newspapers and E-Journals}

Today the internet is becoming more and more important as a source of information. And so the interest into websites providing information is prospering too. Many of these informational websites can be regarded as newspapers as they display their information like articles in paper-based newspapers. Today such online newspapers can be found in almost every area of the web covering almost any existing topic. But the number of online newspapers is still constantly growing. This paper is written to discuss aspects like advantages and problems of these internet-based magazines. The discussion starts with enewspapers in general and then continues with an example for such online newspapers. The used example is ZeWIC, which means "Zeitung der Wirtschaftsinformatik in Clausthal". The name can be translated like "Newspaper of Business Informatics at the Technical University of Clausthal".

\section{Informational Added Values of Online Newspapers and E-Journals}

According to the electronic outline of online newspapers and e-journals - like ZeWIC - there are certain additional benefits commonly referred to added values. These added values are not always planned side effects but they increase the benefits - both the readers' and the publisher's - in some cases to a great extent. Depending on which way the added values are accomplished they can be divided into several categories (Becker, 1995). Some of these added

Material published as part of these proceedings, either on-line or in print, is copyrighted by Informing Science. Permission to make digital or paper copy of part or all of these works for personal or classroom use is granted without fee provided that the copies are not made or distributed for profit or commercial advantage AND that copies 1) bear this notice in full and 2) give the full citation on the first page. It is permissible to abstract these works so long as credit is given. To copy in all other cases or to republish or to post on a server or to redistribute to lists requires specific permission from the publisher at Publisher@InformingScience.org values and their categories will be presented here: Comparative added values: Through the way of electronic presentation advantages can be achieved by adding more explanatory power to the articles using a suitable integration (e. g. by HTML linking) of documents, figures, programs and other data (Muenz, 2002). Besides the articles' contents can be supported efficiently by us- 
ing these methods. In paper-based newspapers and magazines these possibilities are severely limited but electronic newspapers and e-journals can tap the full potential of these measures.

Added values with efficient effects: Publishing the online version on an electronic way through the internet means in addition economical advantages too. First of all, the printing costs are decreased which can be - especially for a mass circulation - significant. Particularly because ZeWIC is designed to be a free of charge source of information primarily for students. In addition the electronic communication media provides the possibility to publish information immediately. This means time savings as well.

Added values with efficiency of labour effects: Like already mentioned at the comparative added values the electronic way of publishing means a multiplicity of possibilities to deal with information in a well controlled way as well as utilising them effectively.

Integrative added values: Combining newspaper-like information like articles with the electronic communication media, the internet, creates a lot of already stated effects. By integrating the possibility of writing letters to the editor gives - in addition to the news system - a forum to the readers in which they can comment and maybe discuss issues regarding business informatics. The letters to the editor also provide a feedback from the readers to the editors about the students' wishes and about improving ZeWIC even more.

Organisational added values: After the only sources of information were various bulletin boards, the news page on the institute's web site as well as several news groups, ZeWIC now means the possibility to access all information summed up and well arranged. Above all this leads to savings in time and ways. In addition it is possible to create a better organisation between the students who are using the same common information media.

Strategic added values: Constant updating of information in ZeWIC provides insights into the modes of operation of professorship for business informatics as well as institute for informatics on a limited scale. Thus, the professorship appears more transparent and is regarded by the students as clearly arranged and student-friendly. Consequently it is possible to adjust the presentation of the information to hit the target group's interests.

Innovative added values: Because the development of electronic newspapers and e-journals dates back not too long, but even still continues, there are again and again new effects appearing and turning out to be innovative and beneficial. That way the information processing for the reader using provided or available mechanisms can be simplified pretty much.

\section{ZeWIC - an Overview}

ZeWIC, the (electronic) newspaper of the department for business informatics at the Technical University Clausthal, is a newspaper-style website about current events and any other news. It provides an actual source of information to the students of business informatics as well as persons interested in this field of study and professorship.

\section{Why Internet?}

Making ZeWIC available to an audience as large as possible and area-wide a paper bound version was purposely abandoned. This is because a paper bound newspaper can only be published in a small area if only little capital is available because printing and publishing costs can increase fast with many print runs. Instead the internet was chosen for publication. By this means interested people can access ZeWIC's informational contents from anywhere in the world without additional expense. 


\section{The Beginnings}

The idea of establishing a newspaper for the professorship for business informatics was born in July of 2002. The aim was to build a source of information for business informatics students. So far they had to search for information on several websites, some newsgroups and a lot of notice-boards. During the implementation the name ZeWIC was invented in August of 2002. On October $1^{\text {st }}, 2002$, ZeWIC went online - just in time to meet the beginning of term. Since then it is becoming more and more popular among students.

ZeWIC's data concepts and the particular implementation will be described in the next chapters.

\section{Data Model}

To have a guideline for the implementation there has to be a set of concepts to at least draw an outline showing the range of the demanded features ZeWIC must provide. Therefore this data model was designed to serve as a specification for ZeWIC's implementation.

\section{Basic Concept of Articles}

The articles are stored in a database. The data model for these articles provides fields for the author, the timestamp of recording, the article category, the headline and the particular content. Here the content is split into two parts, public content and private content (see also figure 1). This split- up seemed convenient, even if it was not really necessary. In this way the enroling author can add potential comments to the article. This comes handy if additional information is required which is only meant for the coauthors, but not for public notice. E. g. if a project is announced in the public part, internal information about the actual progress can be given in the private part of an article. There are two more fields within the data model designed for the timeliness of the articles. In one of them the authors can define an article to be valid or expired. If an article announces e.g. a special event, it can be defined as expired when this event is over. The other field is made for removing expired or incorrect articles from publication. For a proper archiving all articles should remain in the database. But if an article proves wrong so it should not be published any more, this field serves the possibility to hide this article. Letters to the editor are a special kind of articles. Here the field for private content is nonexistent. But there are some additions (see also figure 1):

Because the authors' data are taken from the user table from the database, there is no need to save their email addresses to the articles. But letters to the editor are written by undefined readers and usually only once by one reader. So it is simply waste to create an extra table for the writers' data. However it is recommended to keep their email addresses if there are questions left. So this is arranged by a field in the letters to the editor table.

There is also an additional field for hold-back time. This is because letters to the editor are to be displayed only for a period of time determined by the writer. Because the letter's current state is predetermined by the hold-back time, the field for the article's validity is inapplicable. 
Furthermore there are several fields for documenting the letter's life cycle. On the one hand it may be important where the letters came from; on the other hand it may be of interest which administrator initiated hiding the letter if hiding was necessary.

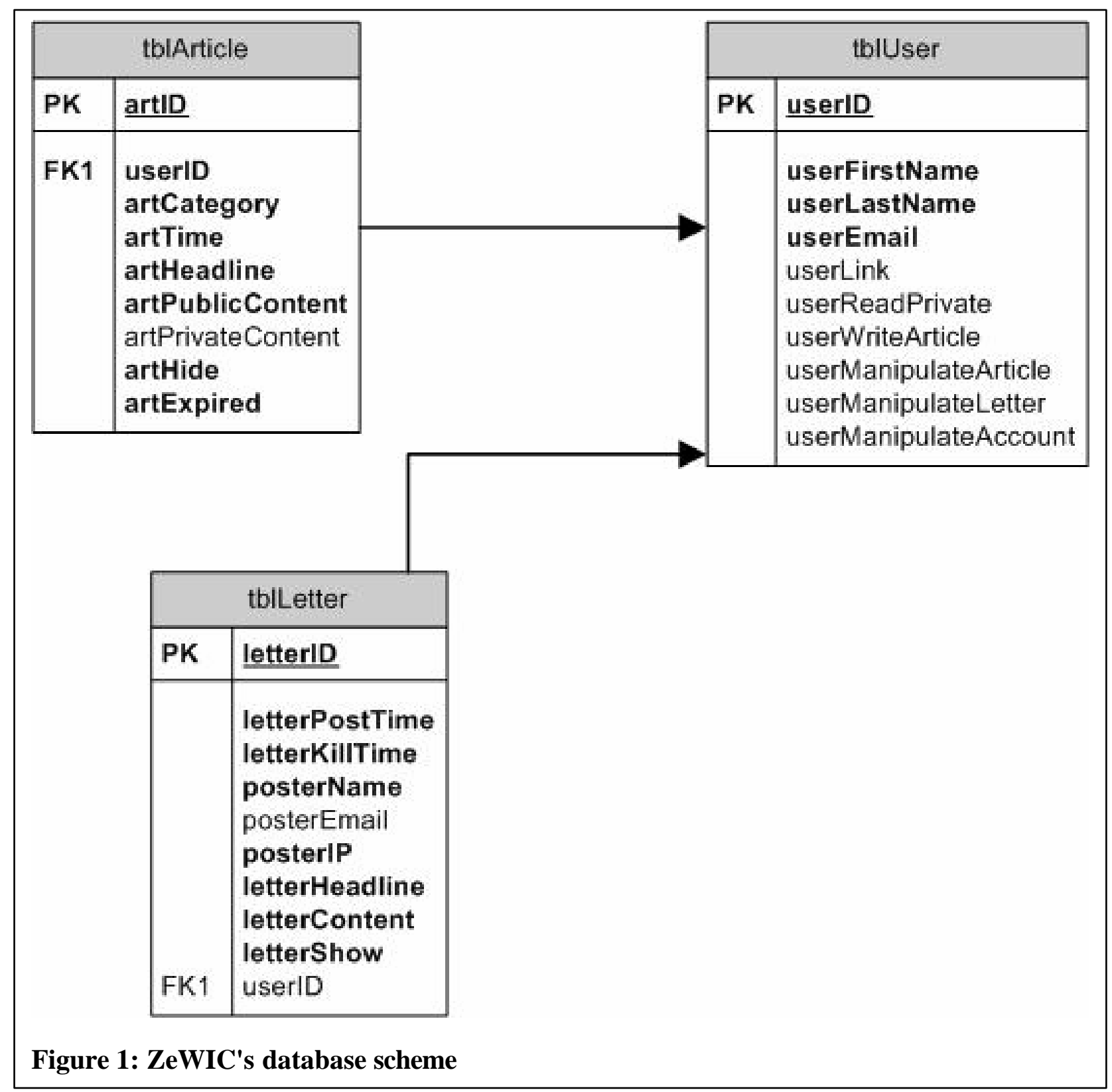

\section{User Group Design}

ZeWIC's users are divided into groups to achieve a certain structuring for accessing its news system. At the moment there are two different user groups:

Ordinary Users (Readers): Every user coming to the ZeWIC website is by default regarded as a normal reader who can browse through the information provided as articles. This standard user group includes all other user groups as it contains any visitor to the website.

Privileged Users (Administrators or Authors): ZeWIC's secure area is only accessible by using a special login. Only a few privileged users are allowed to log on to this secure area to manage ZeWIC. This administration job includes above all writing and managing articles as well as managing letters to the editor and possibly creating user accounts for new authors. 
The current partitioning into two user groups is just a short-term intermediate phase. Because even during running operation ZeWIC is constantly under construction these two user groups are to be different iated more precisely.

\section{GUI Design}

Because the overall design of data representation was predetermined by a certain frame set to achieve a corporate design, there were only the details in the representation left to design. In the same way the headlines for the categories as well as for the articles were suited to fit this corporate design. The articles' contents are arranged in a grouped style with normal black fonts on white background. The purpose of this is to make ZeWIC easily readable and presentable even on PCs with a low colour depth and a low resolution display. Also an authentic appearance is persistent by using this article style. This is of particular importance to a legitimate newspaper.

\section{Implementation of ZeWIC}

ZeWIC is programmed mostly using PHP scripts (PHP is short for "PHP: Hypertext Pre-Processor". This scripting language allows the designer to program server-based scripts that produce HTML, XHTML or any other code dynamically to be sent out to the user's web browser.). They produce dynamically HTML or XHTML documents on demand which are then presented to the reader (Boumphrey, 2000). The XHTML documents should remain as dynamic as possible, so the fonts are formatted using CSS (Cascading Style Sheets, a method to put font style instructions into a separated file to allow several documents to access these instructions.). This is made to keep the type face consistent and uniform as well as straightforwardly alterable. An Apache (Apache Server comes from "A Patchy Server" as it was based on some existing code and a series of "patch files". It has been the most popular web server on the Internet since April of 1996.) web server is used for publication of ZeWIC. This Apache server has a PHP module which is necessary for running PHP scripts. It runs on a Server with RedHat Linux Operating System. Articles, letters to the editor and user management are stored in a MySQL database (Today MySQL is the most popular Open Source database server.). The corresponding MySQL database server is running on the same server as the Apache web server (Eilebrecht, 1998). To ensure that user and management data is not intercepted by unauthorized persons any data interchange from and to ZeWIC's login area (management area) passes encrypted using SSL (Secure Socket Layer, the most

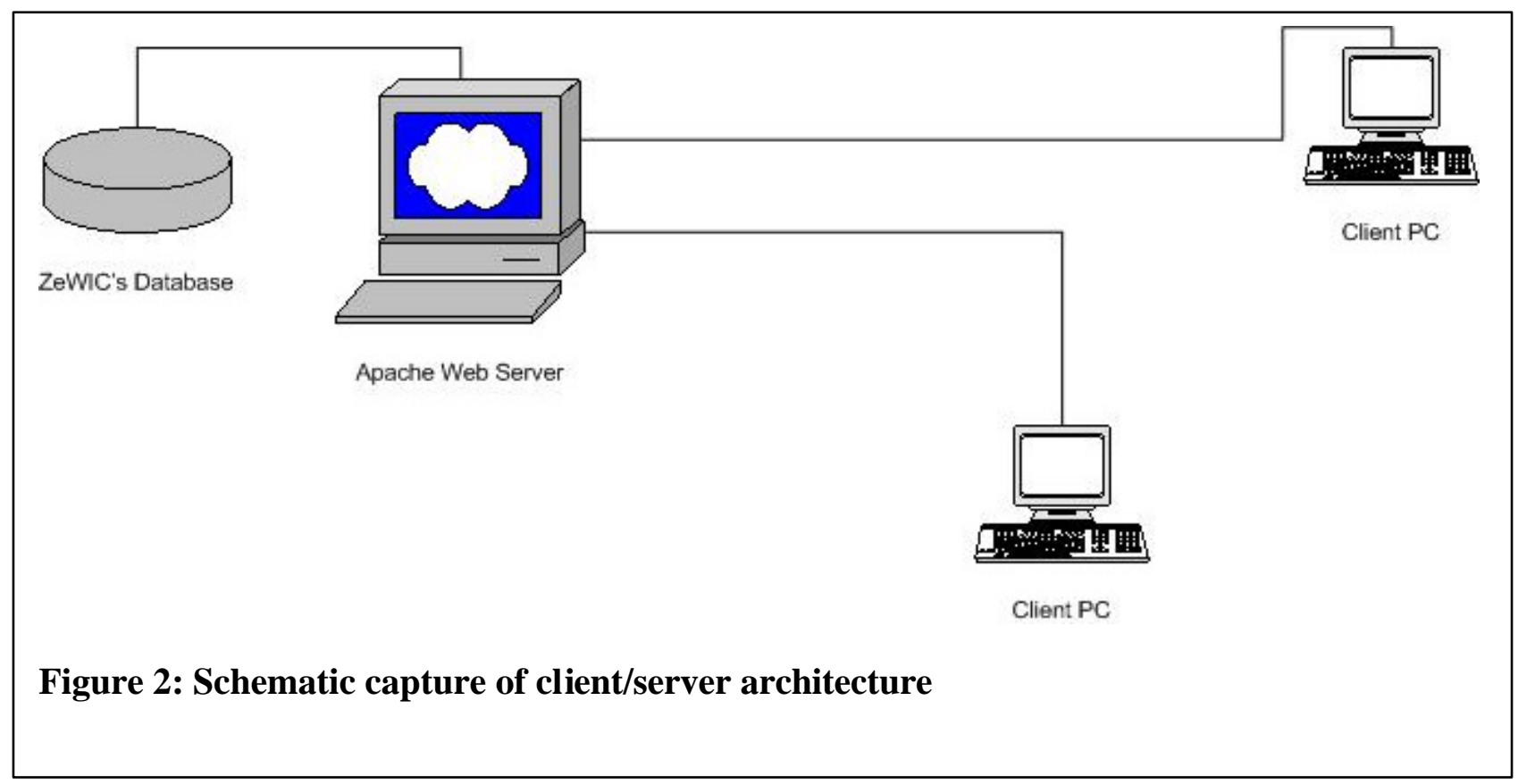


commonly used encryption system on the internet.) encryption. The corresponding module is integrated into the Apache web server as well.

\section{Client / Server Architecture}

Because ZeWIC is based on the web, the used server is an Apache web server and a MySQL database (Greenspan, 2001). This web server retrieves ZeWIC's essential contents from the database and prepares them with the help of PHP scripts to be displayed in HTML / XHTML. Here the web server software is running on the same server as the database management software. It also contains the data from the database. This situation is not necessary (see figure 2), it causally evolves from given circumstances. Also any PC with a web connection comes into question being a client because ZeWIC is based on the WWW. This is due to the fact that ZeWIC's information can be displayed at the client by using a common web browser.

\section{Implementation of User Access Control}

The public articles in ZeWIC can be accessed by any user (user groups), readers as well as administrators who are included in the readers' user group. But because the administration of ZeWIC should only occur by the authorized users (administrators), accessing the secure area is exclusively possible using their login. This login procedure is temporarily realised by HTTP Access Control (HTTP Access Control means there is a plain text file ".htaccess" in a directory. This file contains data about giving access to the other files in that directory. This includes e. g. IP address ranges as well as user access control. User access control is achieved by referring to a user file (usually ".htusers") and a user group file (us ually ".htgroups") if required. Now access to single files can be set by allowing access only for certain users or user groups.). This means the files in the secure area are protected by a ".htaccess" file which refers to a ".htusers" file (The user file for HTTP Access Control is a plain text file containing all users' login names and (in this case encrypted) passwords.) and a ".htgroups" file (The user group file assigns users from the user file to user groups. It is a plain text file too.). These user and group files are generated from data in the database by PHP scripts (Krause, 2001). The implementation of user access control will soon be changed to take place by using a specific database, as elaborated later.

\section{Articles in the online Newspaper}

ZeWIC's articles are stored in a MySQL database. They are recorded by the authors into this database. From the database the articles are fetched on demand by a reader and prepared by a PHP script so they are displayed one after another in a single row table. This table is contained in an HTML document. They are formatted using Cascading Style Sheets (Meyer, 2001). For displaying the articles they are arranged by topicality in descending order. This means the newest articles will be shown first, so the readers won't need to scroll down to see the latest news.

\section{Article Categories}

The categories are realised by a field in the article's data record. Depending on this field's content the articles, according to the requested category, are fetched from the database and displayed to the reader. During the enrolment of an article, the associated category is inserted into the corresponding field by the executing PHP script (Leierer, 2001). Thus, the categories are not implemented dynamically. But this solution will change to achieve even more flexibility in usage of the provided categories. 


\section{Archive}

Because the articles are stored in a database, as a matter of course it is possible to have a view on older articles like a kind of archive. New articles are added constantly, and only the latest twenty of them are displayed. But the older articles are not deleted or removed any way else from the database. Thus, it is possible to retrieve and display older articles from the database instead of the mentioned twenty latest. And because the articles are stored in the database in plain text style, there is no problem with changing ZeWIC's appearance as the articles are displayed in the currently used style.

\section{Letters to the Editor}

To ensure a feedback from the readers ZeWIC provides the possibility for any user to send a public letter to the editor. These are - as well as the articles - stored in the database and retrieved from there and displayed on demand. But there is some specialties about the letters to the editor:

The letter's writer can determine a hold-back time up to 30 days. For this determined time the letter is shown, afterwards no more. But it is kept in the database for documentary reasons.

Also one of the editors will get a copy of the letter by email. This enables the editors to react quickly. Such a reaction may simply be an answer. And if the letter to the editor includes a suggestion for improvement, it can be discussed within the editorial staff and then be realised. The letter can also be hidden if necessary. This option is to prevent the publication of inadequate contents, but it should not be misemployed to achieve a kind of censorship.

\section{Imprint}

As it is part of the nature of newspapers, ZeWIC also has a masthead. It includes the usual information like the publisher, the publisher's postal address, the editorial officer and the person in charge of the online version. Because this masthead's content is changing very rarely only, it consists of a static HTML document as there is no dynamic features necessary.

\section{ZeWIC's Currently Planned Improvements}

Still there are some aspects of the implementation left in some kind of stable interim stage, such as mentioned above regarding user access control. To enhance ZeWIC's significance as well as clarity its implementation is constantly improved. This section is to explain the improvements to be done in a medium-term period of time.

\section{“Newsletter” by Mail}

A number of readers suggested to send new articles by email directly while enroling them. These email should be sent to a list of subscribed readers like a kind of "newsletter". In this way the students will be adverted of the latest news immediately. Regularly looking up the website for news will be dispensable. Insofar as this newsletter is not only convenient, it also saves the time used to look up the website just to see nothing has changed. The other way around the students will not miss important and maybe timecritical news.

Admittedly, at the moment there is the question to what extent such a newsletter should be realised and if there should be one at all. The technical aspects of the implementation are also undecided. Because circular mails of this kind are often regarded as spam (Unrequested mass email and mass advertising which is disturbing to a high degree is commonly called spam.), there is the need to decide explicitly if all articles should be mailed immediately or if less important articles should be pre-marked for sending and then sent later attached to more important ones. And then, there is the question how the users should 
be added securely to the list. The problem ponders between security and simpleness, so that it can be operated easily by the reader but not misemployed to disturb someone else by simply adding their email address.

The technical aspects of a newsletter have several options as well. On the one hand it is possible to delegate the management of the list to a particular list server and then send the newsletter to an ordinary mailing list. In this way the subscription problem will be solved by the security options provided by the list server. On the other hand the user email list management can occur using the already existing database.

\section{Attachments}

In general it is insufficient to limit a newspaper exclusively to simple text with headlines. Usually paper based newspapers and magazines make use of photographs as well as illustrations and figures to support articles' contents and sometimes even their authenticity or credibility, too. Likewise it should be possible for electronic newspapers to prove articles using graphics or other documents, or at least to reference to such additional information. At the moment the authors only have the option to refer to further reading information by adding them using an HTML link. But obviously this proceeding can be really exhausting. Hence it should soon be possible to include such attachments into articles. How this functionality will be realized is yet to decide. One option would be uploading files to the website's web space, uploading to other servers or even an XML (XML: eXtensible Markup Language. A mark-up language to separate the documents contents from their presentation style.) style implementation of linking.

\section{Searching the Articles for Information}

When ZeWIC's size and amount of articles will have grown to a high and complex degree, it should still be possible for the readers to search well directed for information in the newer as well as the older articles. So it would be an advantage to provide a searching functionality to process the articles in the database. Using this function, the articles can be scanned for requested key words. Searching can occur optionally through all articles, or in a time range or category specified by the reader. In this way an investigation of ZeWIC's articles can be supported efficiently.

\section{Differentiated User Rights}

As described below the segmentation of ZeWIC's users into two groups, readers and administrators, is acceptable but not really sufficient. The obvious problem is how to arrange the administrators' authorisations. If there are only a few administrators, controlling anyone's responsibilities is pretty easy. But if there are too many authorized users, there will soon be overlappings regarding the administrators' ind ividual authority or interests as article authors and managers as well as user account managers. This will surely lead to conflicts which may split the editorial staff.

From this consideration results, the need for further differentiation of the author and manager rights for the privileged user is strongly required. In doing so, there must be a balance between the number of nuances and the range for their authorities. Regarding all aspects, user rights should at least be distinguished between three groups: authors resp. managers of the articles, managers of the letters to the editor, and administrators of the user accounts.

During the course of detailing the user rights, the access control management will be converted from HTTP Access Control to a system strictly based on the database mentioned above (Schröder, 2001). The required fields are already provided in that database, as figure 1 shows. Thereby ZeWIC's dependency on the web server's file system will be eliminated (The server's file system is a major weak point in ZeWIC user access security structure. To use HTTP Access Control the .htuser and .htgroup files must 
be writeable for the PHP scripts. Unfortunately this makes them writeable for some other user of the server, too.). Instead ZeWIC's implementation will be encapsulated even more. Thus, it will be almost platform-independent. Of course assuming there is an Apache web server with SSL and PHP modules as well as a MySQL database available (Kofler, 2001).

\section{Commenting and Post-Editing Articles}

Many times the author or one of the other authors sees the demand for changing something within an article. But this option to change an article's original content should be impossible to ensure a traceability which must not be affected by a manipulation afterwards. In ZeWIC's current version there is only a workaround to achieve such a change by simply publishing the same article again but with the change and hiding the one without. But to have a possibility to refer to an article's content, the authors should have a way to comment existing articles. It is declared that if an editor wants to add a note or a longer text to an existing article this text will be attached to the articles content marked with the name of the editor and the date the addition was made. But it must be clearly separated from the original content to provide an obvious correlation between article, comment, and their authors.

\section{Dynamic Classification of the Articles to Categories}

In the course of using ZeWIC some details catch an author's eye, such as the fact that the categories are assigned statically. So if an author wants to assign an article to two categories, a common workaround is to put this article into the database twice, one time with one category, the other time with another. To avoid this redundancy of articles, there will soon be a new correlation table to connect articles and categories. In this way assigning articles to categories will be handled much more dynamically and thus articles can appear in more than one category without being inserted into the database several times. This also means a practical advance to the newsletter. If an article is put twice into the database, it will also be sent twice by email. With the dynamic assignment the article will only be sent once.

\section{Summary and Perspective}

This paper gives an overview of ZeWIC, the (online) newspaper of the professorship for business informatics at the Institute of Computer Science at the Technical University of Clausthal, as an example for websites with in the meantime more and more growing importance, similar to online newspapers and ejournals. These online magazines provide information like paper-based newspapers, but they have more possibilities regarding timeliness, references and presentation styles. In this context problems like editorial and security matters must be mentioned. ZeWIC, as the used example to discuss the possibilities of such e-newspapers, can be used to show many of their advantages compared to paper-based newspapers but also their problems. First ZeWIC's data model has been introduced in order to show the concept which constitutes the background and precondition for the implementation which was presented as well.

Self-evidently such a major project of designing an electronic newspaper can never really succeed to a final state. They stay in a constant devoloping process. This also goes for ZeWIC. It still passes through an evolution from a simple listing of articles to a more and more sophisticated system including editorial as well as user-friendly elements. Therefore, there are constantly new additions and improvements to be made. This paper also gives a general survey of the changes planned for the next time. 


\section{References}

Becker, G. (1995). Information, Kommunikationsformen. Märkte und Arbeitsweisen. Stuttgart: Franzis.

Boumphrey, F. (2000). Beginning XHTML: A comprehensive guide for the beginner to the new XHTML. Birmingham: Wrox Press.

Eilebrecht, L. (1998). Apache Web-Server: Installation \& Modulbeschreibungen, Konfiguration \& Administration. Sicherheitsaspekte, Apache-SSL. Bonn: Thomson.

Greenspan, J. (2001). MySQL-PHP-Datenbankanwendungen: Fundierte Einführung. In MySQL und PHP. Bonn: mitpVerlag.

Kofler, M. (2001). MySQL: Einfuehrung, Programmierung, Referenz. Munich: Addison-Wesley.

Krause, J. (2001). Programmieren lernen in PHP 4: Ein kompakter Einstieg in die Webserver. Munich: Hanser.

Leierer, G. (2001). PHP 4 \& MySQL. Düsseldorf: Data Becker.

Meyer, E. (2001). CSS Pocket Reference: Visual Styles for HTML. Beijing: O’Reilly.

Muenz, S. (2002). HTML 4.01 - XHTML 1.0/1.1 - JavaScript - DHTML - CSS. Stuttgart: Franzis.

Schröder, J. (2001). Webserver betreiben: HTTP und Apache. Grundlagen, Konzepte, Lösungen. Heidelberg: dpunkt-Verlag.

\section{Biographies}

Nils Heyer studies business informatics at the Technical University of Clausthal. He is currently working as a scientific auxiliary personnel within the department of business informatics at the Technical University of Clausthal.

Dr. Jorge Carlos Marx Gómez studied computer engineering and industrial engineering at the Technical University of Applied Sciences of Berlin. He is a lecturer and researcher at the Otto-von-GuerickeUniversität Magdeburg where he also obtained a PhD degree in business information systems with the work Computer-based Approaches to Forecast Returns of Scrapped Products to Recycling. Currently he is a visiting professor for business informatics at the Technical University of Clausthal. His research interests include business information systems, e-Commerce, material flow management systems, life cycle assessment, eco-balancing, environmental reporting, recycling program planning, disassembly pla nning and control, simulation and neuro-fuzzy-systems. 